\title{
Intercultural Competence Development
}

\section{Research Questions:}

- How do students become

interculturally competent ?

- What should educators do to facilitate that process?

- And how do we know ?

\section{Research Objectives:}

- Preparing graduates for an international \& intercultural workplace.

- Preparing educators for international education.

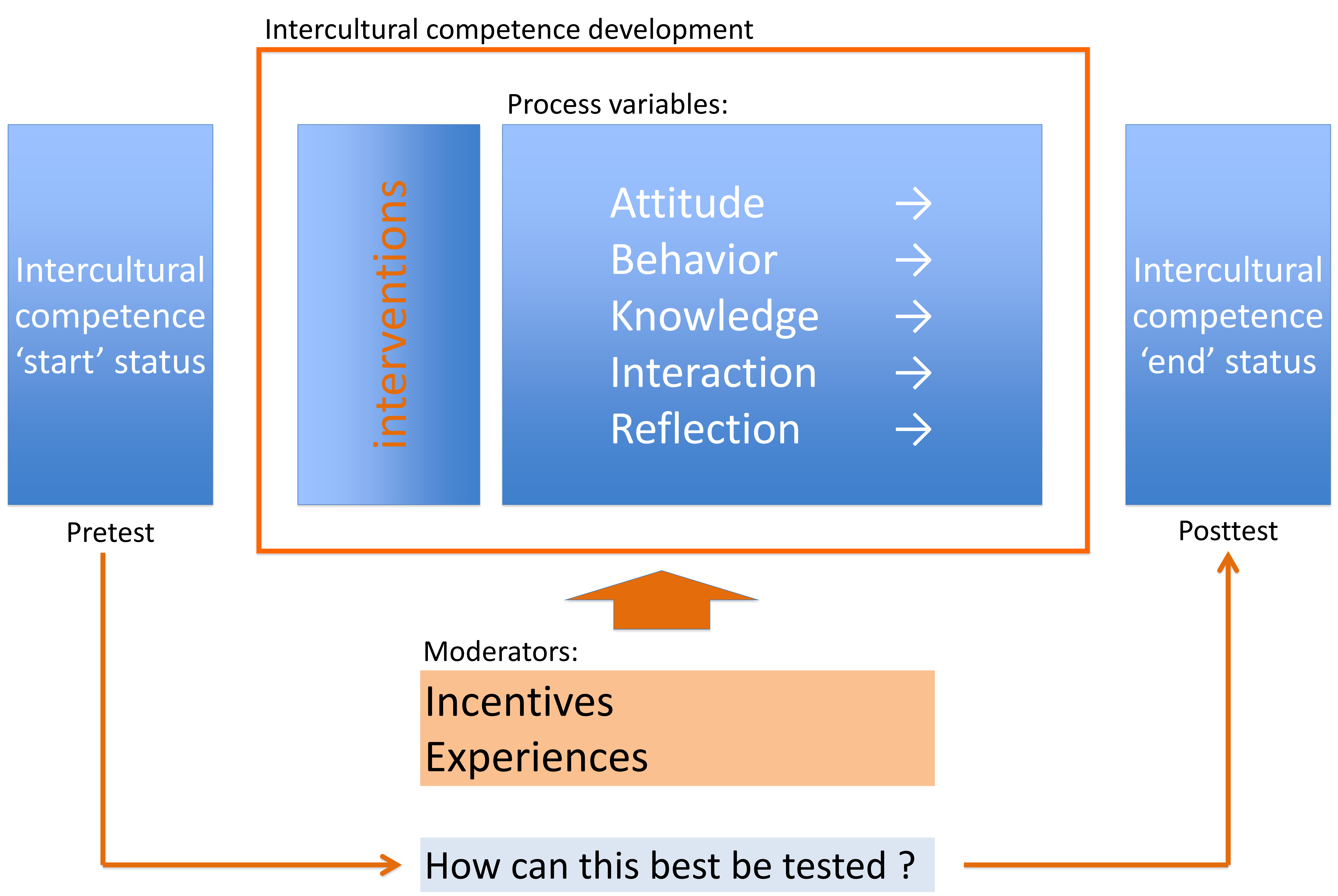

First results: post-testing 10 educators showed a shift of 8 points on a 90point scale into a more developed stage of IC. In comparison with other empirical research that made use of the same test this gain can be seen as meaningful (Vande Berg et al., 2012). 